\title{
The coronary stent story
}

\author{
Leo Finci, MD, MSc, PhD, FMH, FESC, FACC.
}

Cardiology Institut Champel, Geneva

Abstract

Key words
The objective of this article is to narrate the story of stent development as witnessed by the author who was present from the very beginning. By the end of eighties, coronary angioplasty (PTCA) had clearly shown its limitations such as abrupt vessel occlusion, dissection and restenosis rate of up to $35 \%$. The Medinvent Company developed a self-expanding-stent that was implanted in a first series of patients by Ulrich Sigwart in Lausanne, Switzerland in 1986. However, the multicenter study in 1989 had disastrous results, with $25 \%$ of stent occlusion rate and restenosis of $>20 \%$ in remained patients. The Palmaz-Schatz stent was first bare-metal stent (BMS) largely used in the world since 1990. The heavy anticoagulation treatment was abolished by A. Colombo in 1993. By 1997, about 17 new models existed, still the abrupt stent occlusion, subacute stent thrombosis (2-4\%), and restenosis (25-30\%), were major problems. Drug-eluting stents (DES) were developed to specifically address the problems of restenosis encountered with BMS. The sirolimus eluting stents used since 2002 have shown better clinical results than paclitaxel eluting stents arriving in 2004, but newcomers using zotaralimus, everolimus and biolimus elusions have arrived showing even better results. Currently, the last generation of stent need only 3 months of dual antiplatelet treatment, bioapsorbale coating is only on ab-luminal side of stent, struts are thin and metallic cage is laser cut hypotube. The case of chronic total coronary occlusion is discussed, as this indication benefited most from the stent development. Bioresorbable vascular scaffolds (BVS) are intended to overcome most drawbacks of stents: the presence of a metallic cage, positive remodelling, and normal vasomotor vessel function, but long-term results are still unknown.

stent, coronary, history, bare metal stent, drug elution, chronic total coronary occlusion, bioresorbable vascular scaffolds

nce upon a time there was a coronary device, named «stent» ${ }^{1}$. Its name comes from a dentist ${ }^{2}$, and a noble German prince coming from the battle-field of restenosis and residing Swiss castle help him to become a stronghold of human coronary vessels ${ }^{3,4}$. Indeed, the stent story is so close to a tale! Since its first clinical use, with several generations of stents, throughout years of enthusiasm, complications and drawbacks ${ }^{5,6}$, stents successfully improved to new scaffolds. The objective of this article is not to scientifically analyze all the phases of stent development, its clinical application and studies; it is rather to narrate the story as witnessed by a man who has been present from the very beginning.

\section{Pre-stent era}

By the end of eighties, coronary angioplasty (PTCA) had clearly showed the limitations (Figure 1). Primary success was relatively acceptable, but there were many drawbacks, such as abrupt vessel occlusion or dissection. In particular the long-term results were limited by the recurrence ${ }^{7,8}$. Many European centres have addressed the question of restenosis after PTCA, as we did

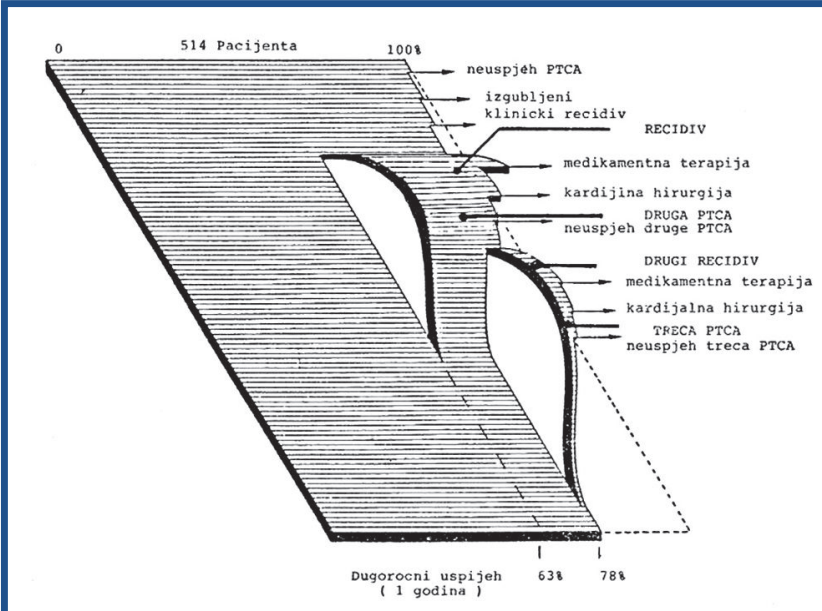

Figure 1. Follow-up of 500 patients after coronary angioplasty (PTCA) - in 1986. Note primary success of only $63 \%$ at one year that reaches $78 \%$ after repeat procedures.

in Geneva ${ }^{9}$ mainly by new drug treatments using different medications, starting with angiogenesis enzyme inhibitors to steroids, but also using technologies such as lasers or atherectomy. I can still remember a patient 


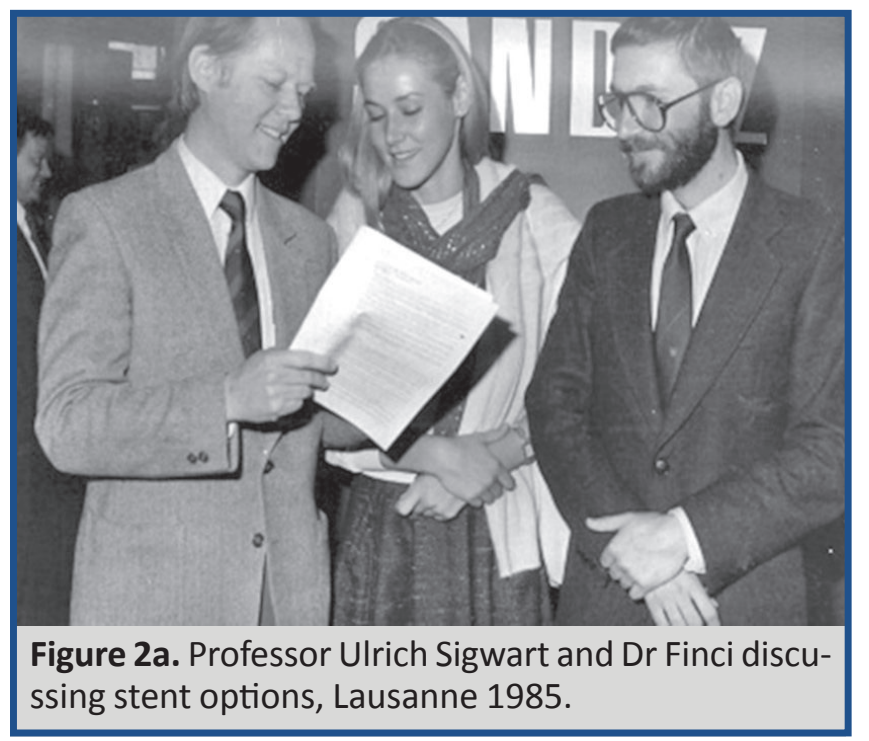

that undertook 11 repeated PTCAs for a proximal LAD lesion, sometimes restenosed, but mainly caused to balloon injury around the lesion.

\section{Early stents}

The Medinvent company located in canton de Vaud, in French Swiss part, was involved with many new technologies, such as artificial skin. With Prof. Rutisahuser, from Geneva University Hospital, we were invited to discuss the stent experience in 1985 - we had a hall out of a problem to find location of the company installed in Swiss mountains, in the middle of the cows! In spite the work that had already been done by Medinvent, the decision was made to continue doing only animal study in Geneva before any human experience could be started. It is only that Ulrich Sigwart, of Lausanne University Hospital who had courage to go on! (Figure 2, A and B). One must admit that it was not an easy task at all. Just to make it more clear to understand: the unit of Experimental Surgery, in Lausanne disposed of non-optimal x-ray equipment, so some of the experimental dogs (to start the experience) had to be stented in a human catheterisation laboratory after regular working hour's (Dr Mirkovitch, experimental surgeon in charge at the time-personal communication).

However, during 1986 total of 19 patients were treated by stent implantation mainly for restenosis after PTCA and acute closure, with 3 complications due to stent thrombosis ${ }^{10}$. The first human implantation was successfully done by Puel in Toulouse early that year in acute setting in a case of abrupt closure. During the first live stent summit in Lausanne in 1987, the audience could also witness the first stent thrombosis - while most of the participants enjoyed their lunch, Sigwart kept so busy in the Cathlab.

In the years that followed, the Wallstent was being used in several European centres, including Rotterdam, London and Geneva (Figure 3) but with disastrous result: from about 100 patients that were treated, stent occlusion occurred in 25 patients, and restenosis in 14 other patients ${ }^{1,11}$.

The new stent player came from across the OceanUSA. Richard Schatz had carefully planned and went on
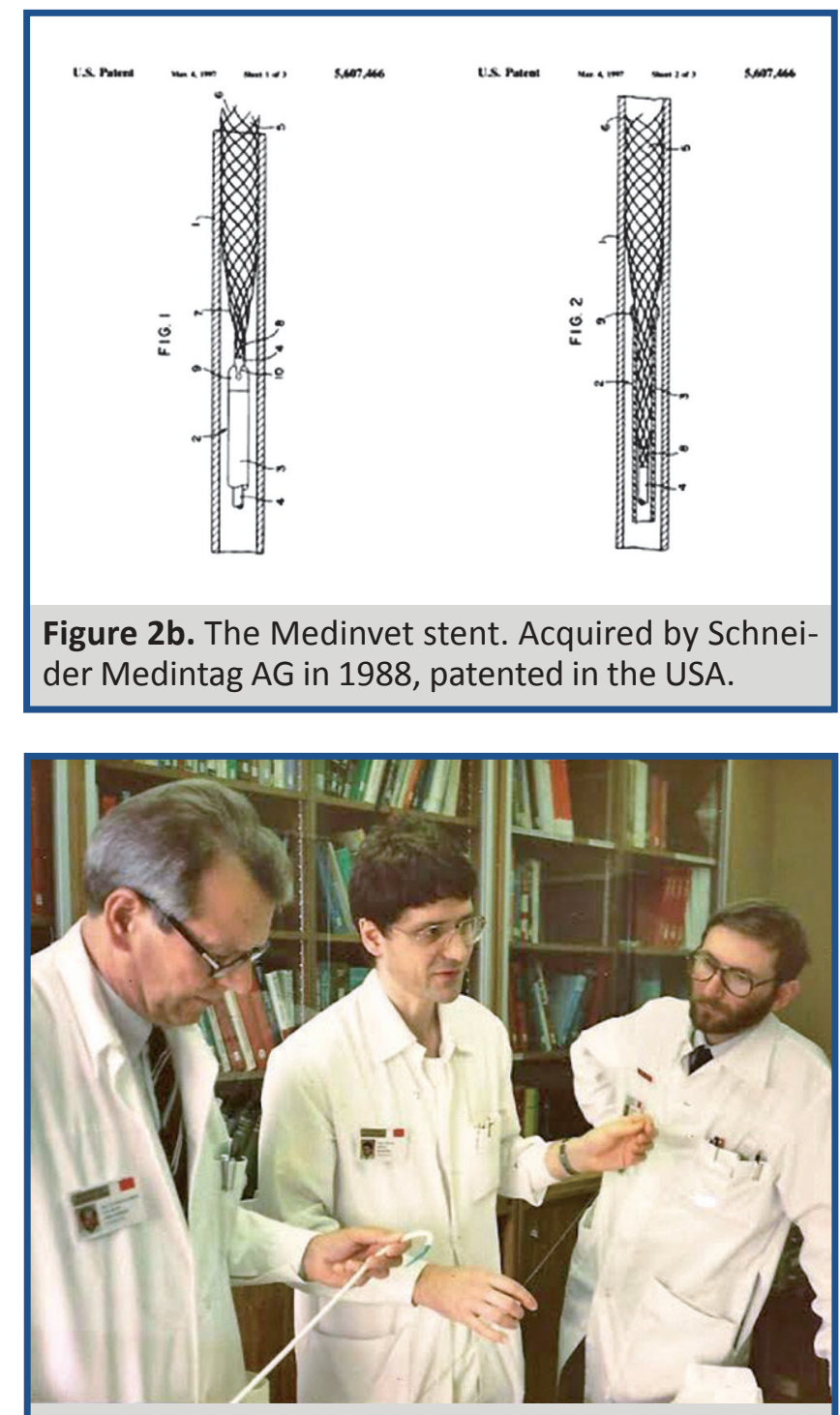

Figure 3. Prof. Rutishauser, Dr B. Meier et Dr Finci, exploring new $\mathrm{PCl}$ material in Geneva University Hospital in 1986

doing studies with a balloon expandable model of an articulated stent ${ }^{12,13}$, available at that time in Europe for clinical use, but not in the USA. Colombo implanted successfully first few stents in 1990, Schatz being present with him in Milan that morning; it happened that Schatz was obliged to leave Milan in the afternoon of the same day, and just after having left Columbus Hospital for the airport the next stented patient had thrombosis! That made a big impact on Colombo, who was going to abolish the anticoagulation regimen for years to come.

The first bear metal stent (BMS) approved in the USA, was the Giantaurco-Rubin stent ${ }^{14}$. Garry Rubin was working at Emory University, Atlanta, and did some animal studies, but at the same time authorised studies on patients. However, he pushed too hard for the time being, got some real problems with the Administration making the stent program almost abolished. Fortunately, hazard wanted that an US Congress Senator suffered from an acute coronary occlusion and Rubin successfully implanted him a stent. The senator made out of it a personal affair and obtained the stent to be officially approved (Rubin-personal communication). 


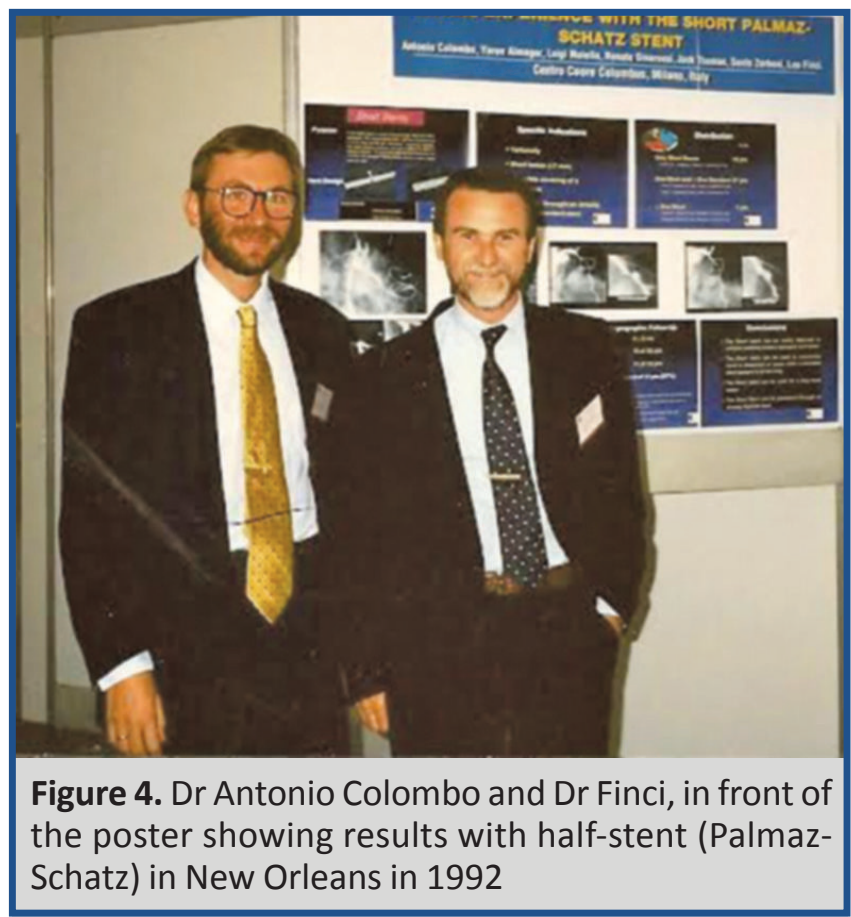

\section{BMS}

The Palmaz-Schatz stent was a relatively rigid device, at first it had to be hand crimp by the operator on a balloon catheter! The device proved difficulties to be placed at the correct site in tortuous vessel and whan operator tried to pull-back the balloon it was rather a mater of chance that stent stayed on-it. There exists probably no single high-volume operator who has not lost a least one stent in patients' circulation during the $\mathrm{PCl}$ at that time, but this phenomenon was largely under reported. In order to improve deliverability, an anecdotal alternative method to stent lesions located in anatomical settings too complex for regular Palmaz-Schatz stent placement was developed in Milan ${ }^{15}$. The method consist of using a disarticulated (one-half) PalmazSchatz stent - as a matter of fact, Colombo (Figure 4) "simply" decided to cut a stent by half at the site of articulation! He obtained significant results in delivering the stent on the exact place of coronary lesion.

The world society of interventional cardiology welcomed the arrival of new stent designs e.g technical details of 17 stent models are presented, in the book of P.W. Serruys ${ }^{16}$ on coronary stents in 1997 . Not only the stent designs and material have evolved over years, but the implantation technique has significantly developed producing a major successful impact. The use of high-pressure balloon inflation (HP), intravascular ultrasound (IVUS) and appropriate antiplatelet therapy have contributed to the abolishment of the need for subsequent anticoagulation, allowing extended stent applications ${ }^{17,18}$. These changes are best shown by Dr Colombo who pioneered this technique $^{19}$. To illustrate that (Figure 5), we compared three groups of patients ${ }^{20}$ having stent implantation throughout the period of technical evolution Group A: no IVUS, no HP, with subsequent anticoagulation treatment $(n=434)$; group B: no IVUS, yes HP, without subsequent anticoagulation treatment $(n=192)$; and group C: yes IVUS, yes HP,

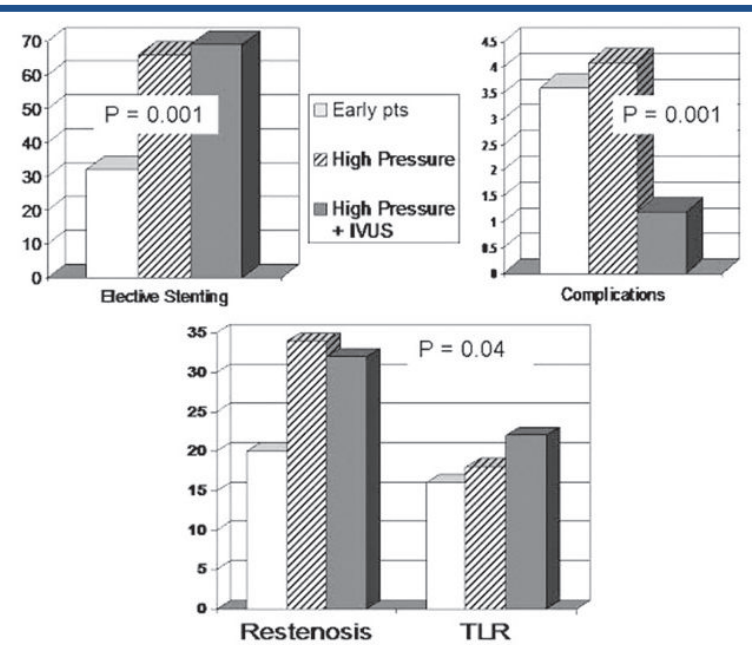

Figure 5. Coronary stenting (BMS) throughout technical evolution: 1992-1999. With the use of IVUS and high balloon pressure there is a change in indications, decrease in complications, with an increase in restenosis and TLR rates with addressing more complex lesions subsets.

without subsequent anticoagulation treatment ( $n=588$ ). The primary success rates were comparable in all groups. There was a clear change in indications for stenting in groups $\mathrm{B}$ and $\mathrm{C}$ compared with group $\mathrm{A}$ (elective stenting: $A=32 \% ; B=66 \% ; C=69 \% ; P<0.0001$ ), in reference vessel size $(A=3.22 \mathrm{~mm} ; B=2.92 \mathrm{~mm} ; C=2.98 \mathrm{~mm} ; P<0.0001)$, and for presence of type $B 2$ and $C$ lesions $(A=57 \% ; B=$ $72 \%$; $C=74 \%$; $P<0.001)$. The complication rate significantly decreased in group $C(A=3.6 \% ; B=4.1 \% ; C=1.2 \%$; $\mathrm{P}<0.001)$ and the mean patient hospital stay decreased to 2 days in groups $B$ and $C$ due to the abolition of the need for anticoagulant treatment. The angiographic restenosis rate increased in groups $B$ and $C(A=20 \% ; B=34 \% ; C=32 \%$; $P<0.001)$. The need for a repeat procedure increased as stenting of more complex lesions and smaller vessels was attempted: target lesion revascularization (TLR) was performed in $16 \%$ of patients in group $A$, in $18 \%$ of group $B$ and in $22 \%$ of group $C(P=0.04$ for $A$ versus $C$ ). Major cardiac events (MACE) occurred in $30-33 \%$ in different groups. The evolving technique of coronary stenting has expanded the spectrum of indications and range of coronary vessels attempted, and decreased the complication rates and hospital stay. However, in less-favourable subsets, additional improvements were needed to affect the long-term outcome ${ }^{21}$. These improvements had to wait the introduction of DES.

Indeed, a word should be said about abolishing the anticoagulation treatment $-A$.Colombo reported the first 80 patients with only aspirin and Ticlopidine treatment after successful stenting in early 1993, just in the course of intensive recruitment of patients for Benestent study, and had a hell of difficulty to convince the European community to adopt the attitude. For example, P. Serruys openly said to him „you will fall from the Himalaya Pick if you are wrong..." and he literary meant that ${ }^{22}$. However, the hard data with IVUS study, corroborated with help of Jonathan Tobis from UCLA led to the international recognition and implementation of Colombo's technique. 
Table 1. Devices currently use in percutaneous coronary interventions ( $\mathrm{PCl})$ with the year of introduction, advantages and draw-backs

\begin{tabular}{|c|c|c|c|c|}
\hline Device & PTCA & BMS & DES & BVS \\
\hline Year & 1977 & 1986 & 2001 & 2009 \\
\hline Advantages & \begin{tabular}{|l} 
- Simple use \\
- vesel preparation \\
before stenting \\
-known long-term results
\end{tabular} & $\begin{array}{l}\text { - limited need for } \\
\text { DAPT } \\
\text { - acceptable price }\end{array}$ & $\begin{array}{l}\text {-TLR reduced } \\
\text { - improved long-term } \\
\text { results compared to BMS }\end{array}$ & $\begin{array}{l}\text { - non permanent implant } \\
\text { - avoid late stent thrombosis } \\
\text { - establish natural vessel } \\
\text { integrity }\end{array}$ \\
\hline Draw-backs & $\begin{array}{l}\text { - acute complications } \\
\text { - restenosis } \\
\text { - residual dissection }\end{array}$ & $\begin{array}{l}\text { - TVR } 20 \% \\
\text {-re-occlusion } \\
\text { - privent lumen } \\
\text { expansion } \\
\text {-interface MRI }\end{array}$ & $\begin{array}{l}\text { - stent thrombosis } \\
(1-3 \%) \\
\text { - Incomplete } \\
\text { endothelisation (RR 18\%) } \\
\text { - permanent implant }\end{array}$ & $\begin{array}{l}\text { - «bulky» implant } \\
\text {-vessel }<2.5 \mathrm{~mm} \text { or }>4 \mathrm{~mm} \\
\text { - Long-term results } \\
\text { unknown }\end{array}$ \\
\hline $\begin{array}{l}\text { Restenosis (\%) } \\
\text { TVR (\%) }\end{array}$ & $\begin{array}{l}30-35 \text { (СТО 40) } \\
30-40\end{array}$ & $\begin{array}{l}20-25 \\
20 \\
\end{array}$ & $\begin{array}{l}7-15 \\
10\end{array}$ & $\begin{array}{l}\text { N.A. } \\
<10 ?\end{array}$ \\
\hline $\begin{array}{l}\text { Long-term } \\
\text { Success (\%) }\end{array}$ & $70-80$ & $85-90$ & $>90$ & $>90-95$ \\
\hline
\end{tabular}

BMS = bear metal stent, BVS = bio absorbable vascular scaffold, DAPT= dual antiplatelet treatment, DES = drug eluting stent, MRI= magnetic resonance, PTCA = balloon angioplasty, TVR = target vessel revascularisation

\section{DES}

With the expanded indications for the use of BMS, such as being a case in small vessel, long-lesions, bifurcations, and diabetics, two major limitations of BMS became cumbersome: subacute stent thrombosis (ST) and stent restenosis with a need for target vessel revascularization (TVR). The metallic stainless steel cage of BMS stent produced a binary stent restenosis of $35-50 \%$ independently of stent model ${ }^{23}$. The brachyterapy was applied in large volume centres - but it was unsuitable (a cathlab in a cathlab!), in particular producing late thrombosis, geographic mismatch, relatively high cost, and requirement of radiation oncologists. Drug-eluting stents (DES) were developed to specifically address the problems of restenosis encountered with BMS (Table 1). The device dispose with three components: metallic platform, polymer coating and antiproliferative drugs (Figure 6).

The first successful DES trials were using Cypher (Cordis Corp, Johnson and Johnson Company, Miami, FL, USA) which led to its approval ${ }^{24,25}$ in Europe in 2002. Soon afterwords, a series of trials enabled commercialisation of paclitaxel eluting Taxus stent (Boston Scientific, Natrick, MA, USA), in 2004. The paclitaxel had somehow higher TLR rate and was used in several studies in the years to come as "non-inferior" stent permiting commercialisation of a new stents of second generation ${ }^{26}$, The Xience V (Abbott, IL, USA) everolimus eluting stent was approved and has been available on market since late 2006. The market penetration of stents was very rapid in Switzerland ${ }^{27}$, only in the course of the year1996 about $50 \%$ of $\mathrm{PCl}$, up to $78 \%$ in 2000 , and $91 \%$ in 2007. Second-generation DES stents have refinod all of the three components: the struts, polymers, and drugs eluted, thereby improved outcomes. Compared with the first generation DES, second-generation devices ${ }^{28}$ lowered the risk of ISR, ST, and mortality. For example ${ }^{29}$, the Swedish Registry on 94.384 patients found 38\% lower risk of restenosis, a $43 \%$ lower risk of definite ST, and a $23 \%$ lower risk of death compared to first genera-

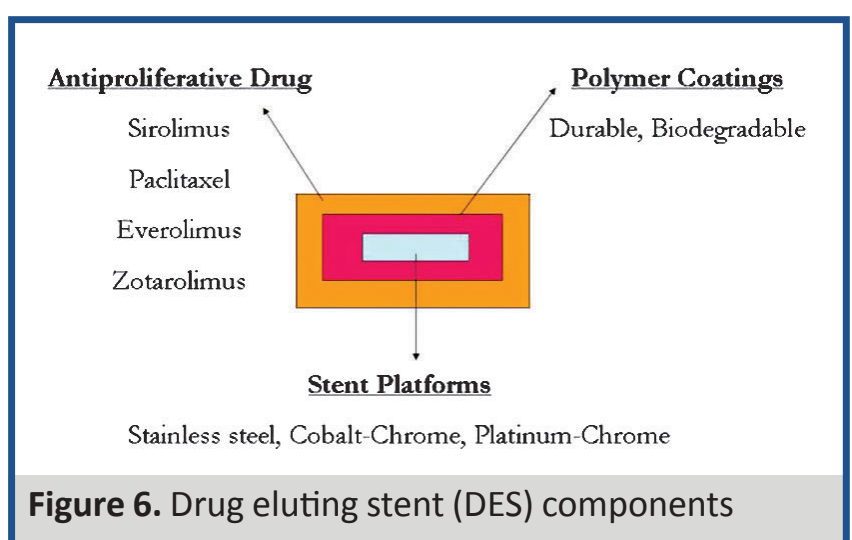

tion DES. Most used second generation stents were Endeavor Resolute (Medtronic) with more biocompatible polymers and Biolimus A9 (Biosense) was a new highlyophilise sirolimus analogue, and Promus Element (Boston Sc.) everolimus with durable polymer.

Currently, the last generation of stent need only 3 months of DAPT, bioapsorbale coating is only on abluminal side of stent, struts are thin and metallic cage is laser cut hypotube. A novel bio absorbable polymer everolimus-eluting stent Synergy (Boston Sc.) was compared with the durable polymer Promus Element. At follow-up of two years ${ }^{28}$, target lesion failure was non-inferior $(6.1 \%$ for Promus vs. 5.5\% for Synergy) with no ST.

There were two events that should be mentioned. In 2006, at the World Congress of Cardiology in Barcelona, E. Camenzind presented ${ }^{30}$ the results of a meta-analysis of randomized clinical studies comparing DES versus BMS, reporting greater incidence of total mortality and $\mathrm{Q}$-wave MI for DES (38\% versus 16\% respectively). Camenzind concluded: „until safer second-generation DES is available, interventional cardiologist should avoid its indiscriminate use"! I was attending the lecture with $\mathrm{Dr}$ Colombo who told me while getting out of the conference room: „Thanks good I have got involved in wine ${ }^{31}$ production". As a matter of fact, the stent implantation rate went down the first time since introduction of DES. Only in the USA it de- 
creased for almost 20\% (from $89 \%$ at the beginning of 2006 to $70 \%$ at the end of the year), as well as in Switzerland (from $82 \%$ in 2006 to $71 \%$ in 2007).

The second event happened during the American College of Cardiology Meeting in 2007 where result of the "Courage" study were presented at the morning Hot-Session showing equality of stenting versus medical treatment in patients with stable angina ${ }^{32}$. During a panel discussion, the evening before official study presentation, Martin Leon publically discovered the study results, correctly undermining its importance - this made more publicity than the study itself! Dr Leon was suspended from ACC activities for two years, just as an excellent football player.

\section{Industrial involvment}

No story in the world is complete without talking about money. The Medinvent stent patent was acquired for about 1 million SFR in 1988 by Schneider Medintag AG, a Swiss company producing balloon catheters, led by Heliane Canepa (who was later honoured the Swiss business woman of the year). The unfavourable result of a multicentre study that followed in 1991 damped this stent for coronary use. The Johnson \& Johnson Company (J\&) was the first to market the „PalmazSchatz" stent, for a sale price about 2.000 dollars a piece. By 1996 the J\&J sold approximate one million stents worldwide with virtually no any competition ${ }^{33}$. Saying that reminds me that, as all authors, I have to relieve my financial disclosures - that unfortunately are none. The market for stents was growing rapidly as coronary stenting overtook PTCA by 1997.

The other medical company, Boston Scientific (BS), which has lost an opportunity to license the PalmazSchatz stent, needed a stent to remain a viable player in the field. So, they had explored relations with other small companies owning stent technology. A slotted tube NIR stent has been designed in Israel by Medinol Company of Kobbi Richter. The stent has many technical advantages over Palmaz -Schatz stent, including flexible closed cell design, improved deliverability and flexibility, and length: $35 \mathrm{~mm}$ long stent compared to $15 \mathrm{~mm}$ standard. In 1995, BS and Medinol have entered into a series of agreements, followed by a low suite. The NIR Stent was used in Europe in 1996 and introduced to the U.S. two years later. It quickly became a major part of BS business. By year 2000, NIR stent sales have grown to about 600 million dollars in worldwide revenue ${ }^{34}$. As a result, Medinol a small startup company has become major player. Case settlement was done by 2005 for 750 million dollars.

DES development and numerous new model (about 30 different Stent in Europe), made the market parts to be shared. The J\&J announced in 2011 abandoning their coronary stent business, just a year after desperate tentative of buying Connor Medsystems for \$1.4B who had developed a beautiful stent model with double drug „reservoirs". The sales of J\&J dropped from \$2.62 billion in 2006 to only $\$ 627$ million in 2012, making the end of the successful financial story.

\section{A case of chronic total coronary occlusion (CTO)}

The rational of opening chronic occlusion is nowadays extremely well established and the one time scepticism of "having an open artery" is over ${ }^{35}$. Patients with an open artery are not only doing well at medium-term compared to the ones with unsuccessful procedure, but their long-term results up to 20 years are improved. Technical advancement in recanalisation material wires and catheters has allowed for the high procedure success but the long-term benefit after stent implantation is clearly due to the new stent development.

We published one of the first articles that demonstrated benefit in patients with successful PTCA of CTO in Geneva Centre ${ }^{36}$. However, coronary angioplasty of CTO has been associated with disappointing results primary success was only $60-70 \%$ and restenosis rate up to $50 \%$ leading to the long term-success in less than half of initially treated population (Figure 6). Technical advancement in wires and material made little impact on results at that time e.g., Magnum wire ${ }^{37}$. The introduction of BMS has improved restenosis rate, still plafond above $20 \%$, with many patients presenting new reclusion at follow-up angiography. The early article in 1995, using BMS published with Dr Colombo, showed still limited improvement with a clinical benefit in about $77 \%$ of patients at follow-up ${ }^{38}$. In a Multinational CTO Registry ${ }^{39}$ on 1.226 patients followed-up to 5 years, the TLR was lower in DES group compared to BMS group (17.2 versus $31.1 \%, p<0.01$ ). A small Canadian study ${ }^{40}$ in 159 patients showed improved event-free survival at 5 years with DES compared to BMS (89.4\% versus $74.8 \%$ respectively). The advancements in technology of guide-wires, micro-catheters and introduction of retrograde approach for recanalisation, in particular coming from Japan, allowed the success rate to increase substantially (currently in an expert hands close to 90\%, O.Katoh personal communication). At the same time, with systematic implantation of DES long-term result improved with restenosis rate below $10 \%$ (Figure 7 ).

Typical examples are patients with good follow-up results after successful recanalization of CTO at previous BASIC Meeting (ref. workshop summary, $7^{\text {th }}$ Basics Plus, Belgrade, April 11-15, 2011) with the help of our guest-

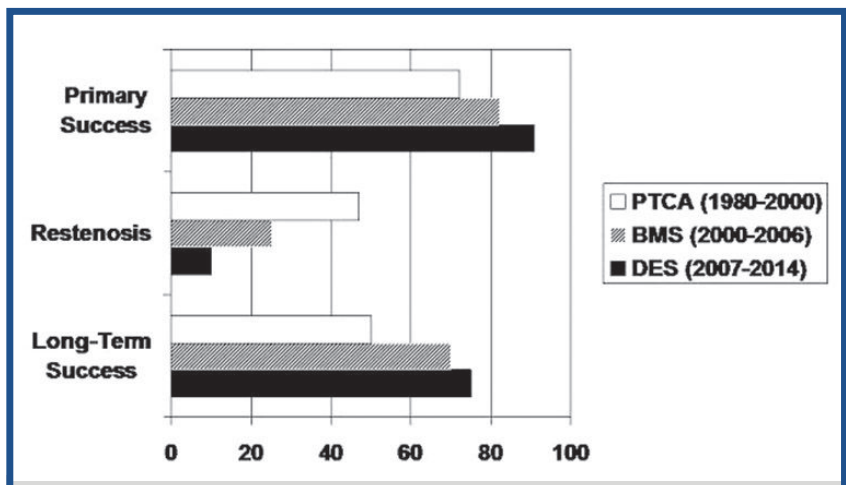

Figure 7. PCl of Chronic Total Coronary Occlusions (CTO). Long-term clinical and angiographic results are improved with development of new stents over time. 
operators, G.Sianos, F. Galassi, Saito, J. Ge et al. Not all DES have an equal follow-up result. In one study ${ }^{41}$ the everolimus-eluting stents were associated with a significantly lower reocclusion rate than were other drugeluting stents (3.0\% vs. $10.1 \% ; p=0.001)$. New DES stents, currently called the $4^{\text {th }}$ generation can even further decrease the recurrence, to less than $10 \%$. The future use of BVS in CTO is certainly challenging, but our excitement at present should be tempered.

\section{Bioresorbable vascular scaffolds (BVS)}

Bioresorbable vascular scaffolds (BVS) are intended to overcome most drawbacks of stents: the permanent presence of a metallic cage that stays on the vessel wall beyond its intended purpose preventing acute recoil and late lumen expansion, positive remodelling, impair vessel geometry and normal vasomotor vessel function, and interface with MRI or MRC. A decrease restenosis and stent thrombosis rates as compared with conventional (metallic) stents is possible. Furthermore, the vessel access for eventual future coronary bypass grafting is maintained ${ }^{42}$.

The use of BVS has largely been in the context of simple proximal lesions of vessel $2.5-4.0 \mathrm{~mm}$ in clinical trials, but the indications have expanded to more complex lesions of 'real-world' including long and diffuse disease. At present, three scaffolds models are available for clinical use.

The balloon expandable Absorb device (Abbott Vascular, Santa Clara, California, US) made from semicrystalline poly-L-lactic acid (PLLA) coated with an amorphous polyD, L-lactide (PDLA) polymer eluting everolimus, has two platinum markers that allow $x$-ray visualization. The single strut thickness is 156 microns, is desorbed in 2-3 years. The Absorb stent is commercially available in Europe.

The Dreams device (Biotronic, Bulach, Switzerland) is a balloon expandable, paclitaxel-eluting magnesium alloy-based bioresorbable coronary stent. The implant is radiolucent and has a single strut thickness of 125 microns. The absorption process takes 9-12 months. Mechanical properties are similar to the current generation of metallic stents including safe over dilatation. It soon receives a CE mark.

The DeSolve stent (Elixir Medical, Sunnyvale, California, US) provides sufficient radial strength for over 3 months and is fully desorbed in 1-2 years. Self-apposant properties allow to over expanding (for $1 \mathrm{~mm}$ without evidence of strut fracture). The Desolve stent received a CE mark in 2013.

Most studies have been done with the Absorb BVS with good clinical results reported up to four years ${ }^{43}$. The Scaffold area by OCT was shown to progressively increase during follow-up with no differences in late lumen loss. The TLR and MACE rates at one-year have been reported as 1.8 and $4.2 \%$, respectively. Stent thrombosis rate was $0.9 \%$. The ongoing Absorb III and IV studies (2250 and 3000 patients, respectively) aim to compare Absorb BVS to Xience Everolimus Eluting Stent (Abbott Vascular, Santa Clara, California, US).

The view of BVS antagonists, such as Haim Lotan's from Hadassah Hospital, Israel includes absence of long-

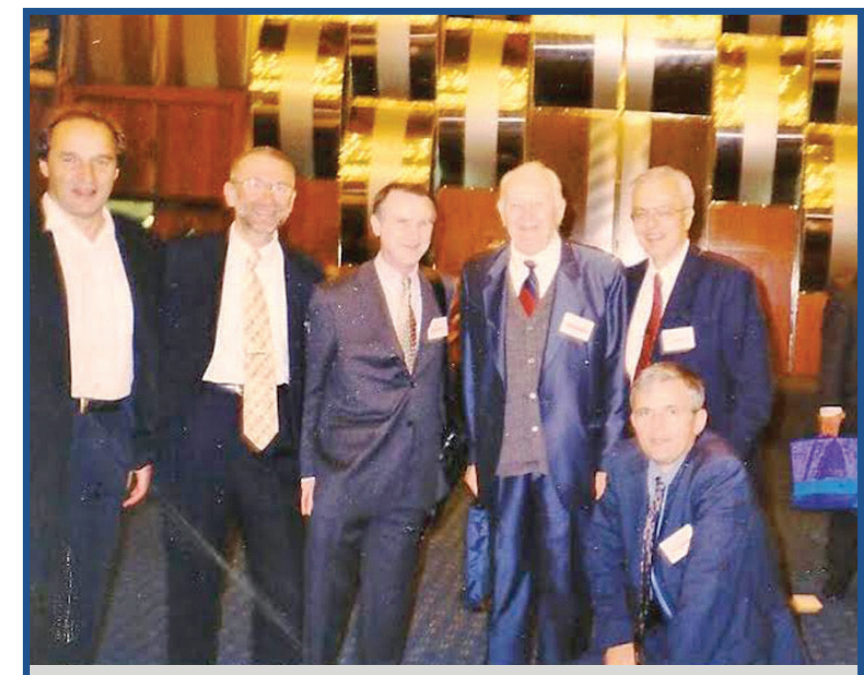

Figure 8. Cardiology School of Belgrade at the Meeting to become BASIC in 2006 (from the right: Prof. Nedeljkovic M, Prof. Ostojic, Prof. Nedeljkovic S., Dr Colombo, Dr Finci, Dr Babic)

term results, current unsuitability for bifurcations, small vessel, or long lesion and of course good result with last generation DES stent. The consensus opinion of Greg Stone is probably the most appropriate at present, keeping with recommended indications for all type of devices ${ }^{44}$.

\section{Acknowledgments}

This article can not be complete without mentioning my Friend, without whom all this would not be possible. I had a chance to be in late'70s in Belgrade, where I did my Master's in Cardiology after successfully accomplishing Medical Military Academy. In early'80s I left for Lausanne, the cradle of coronary interventions, with Ulrich Sigwart the source of my admiration. The time at Geneva University Hospital, with Professor Rutisahuser and Bernhard Meier, the teacher and the pupil of A. Gruentzig the conceiving farther of PTCA, was extremely fruitful and successful with its ups-and-downs; and than comes Antonio Colombo, whose unconditional friendship was both professional and pleasant. Not to forget my "second" home, Belgrade Heart School, my friends since-ever Professors Misa Ostojic and Milan Nedeljkovic, as well as my „professional brothers”: G. Stankovic, B. Beleslin, S. Stojkovic, P. Seferovic, with the special tribute to late Prof. Srecko Nedeljkovic (Figure 8). Talking about the "Second" home raises a question of my "first" home ${ }^{45}$, but that - that belongs to another story!

\section{References}

1. Ruygrok PN, Serruys PW. Intracoronary Stenting: from concept to custom. Circulation 1996; 94 :882-890.

2. Charles Stent (1845-1901) an English. http://circ.ahajournals. org/content/94/5/882.figures-only

3. CV. Ulrich Sigwart. http://en.wikipedia.org/wiki/Ulrich_Sigwart

4. Chateaux Suisse. http://www.bioley-magnoux.ch/typo3/index.php?id=45

5. Topol EJ. Caveats about elective stenting. N Engl J Med 1994;331:539-541. 
6. Curfman GD, Morrissey S, Jarcho JA, Drazen JM. Drug-Eluting Coronary Stents. Promise and Uncertainty. N Engl J Med 2007; 356:1059-1060

7. Leo Finci. »Pluritrunkularna koronarna angioplastika », doktorska teza, Medicinski fakultet, Universitet u Beogradu, 1986

8. Finci L, Meier B, Steffenino G, Urban P, Rutishauser W. Restenosis and repeat coronary angioplasty in Geneva. Eur Heart J. 1988;9 Suppl C:11-3.

9. Finci L, Höfling B, Ludwig B, Bulitta M, Steffenino G, Etti H, Meier $B$. Sulotroban during and after coronary angioplasty. A doubleblind, placebo controlled study. Z Kardiol. 1989; 78 Suppl 3:50-4

10. U. Sigwart: Endoluminal Stenting, W. B. Saunders 1996

11. Serruys PW, Strauss BH, Beatt KJ, Bertrand ME, Puel J, Rickards AF, Meier B, Goy JJ, Vogt P, Kappenberger L, Sigwart U. Angiographic follow-up after placement of a self-expanding coronary artery stent. N Engl J Med. 1991; 324:13-17

12. Schatz R. A view of vascular stents. Circulation. 1989; 79:445-457.

13. Schatz RA, Baim DS, Leon M, Ellis SG, Goldberg S, Hirshfeld JW, Cleman MW, Cabin HS, Walker C, Stagg J, Buchbinder M, Teirstein PS, Topol EJ, Savage M, Perez JA, Curry C, Whitworth H, Sousa JE, Tio F, Almagor Y, Ponder R, Penn IM, Leonard B, Levine SL, Fish D, Palmaz JC. Clinical experience with the Palmaz-Schatz coronary stent: initial results of a multicenter study. Circulation. 1991;83:148-161

14. Roubin GS, Cannon AD, Agrawal SK, Macander PJ, Dean LS, Baxley WA, Breland J. Intracoronary stenting for acute and threatened closure complicating percutaneous transluminal coronary angioplasty. Circulation. 1992; 85:916-927.

15. Colombo A, Hall P, Thomas J, Almagor Y, Finci L. Initial experience with the disarticulated (one-half) Palmaz-Schatz stent: a technical report. Cathet Cardiovasc Diagn 1992; 25(4):304-8.

16. Serruys PW. Handbook of coronary stents. Martin Dunitz Ltd 1997

17. Colombo A, Finci L. A simple step towards better stent deployment. J Invasive Cardiol 2002; 14(5):227-9.

18. Nakamura S, Colombo A, Gaglione S, Almagor Y, Goldberg SL, Maiello L, Finci L, Tobis JM. Intracoronary ultrasound observations during stent implantation. Circulation. 1994; 89: 2026-2034

19. Colombo A, Hall P, Nakamura S, Almagor Y, Maiello L, Martini G, Gaglione A, Goldberg SL, Tobis JM. Intracoronary stenting without anticoagulation accomplished with intravascular ultrasound guidance. Circulation. 1995; 91: 1676-1688.

20. Finci L, Ferraro M, Kobayashi Y, Gregorio Jd J, Moussa I, Albiero R, Di L, Kobayashi N, Martini G, Tucci G, Recchia M, Di Mario C, Colombo A. Coronary stent implantation throughout technical evolution: immediate and follow-up results. Int J Cardiovasc Intervent 1998;1(1):29-39.

21. Finci L, Ferraro M, Nishida T, Albiero R, Corvaja N, Vaghetti M, Stankovic G, Recchia M, Di Mario C, Colombo A. Coronary stenting beyond standard indications. Immediate and follow-up results. Ital Heart J. 2000; 1(11):739-48.

22. Serruys PW. Navigating stent era from bare metal to drug eluting stent. The transformation of PCl. Plenary Session 12, State of the art lecture. European Congress of Cardiology, 2013.

23. Huibregtse B, Granada JF. New DES Platforms. Does the metal alloy matter. Cardiac Interventions Today. 2011; 35-38

24. Serruys PW, de Jaegere P, Kiemeneij F, Macaya C, Rutsch W, Heyndrickx G, Emanuelsson H, Marco J, Legrand V, Materne P, Belardi J, Sigwart U, Colombo A, Goy J-J, van den Huevel P, Delcan J, Morel MA, for the BENESTENT Study Group. A comparison of balloon expandable stent implantation with balloon angioplasty in patients with coronary artery disease. $\mathrm{N}$ Engl J Med 1994;331:489-495

25. Fischman DL, Leon MB, Baim D, Schatz RA, Penn I, Detre K, Savage MP, Veltri L, Ricci D, Nobuyoshi M, Cleman M, Heuser R, Al- mond D, Teirstein P, Fish D, Colombo A, Brinker J, Moses J, Hirshfeld J, Bailey S, Ellis S, Rake R, Goldberg S. A randomized comparison of coronary stent placement and balloon angioplasty in the treatment of coronary artery disease. N Engl I Med 1994; 331:496-501.

26. Bertrand M, Regnier C. Major Advances in Cardiology. L.E.N. Medical Paris France 2012

27. Maeder MT, Windecker S, Roffi M, Kaiser CA, Stauffer JC, Pedrazzini G, Rickli H. Interventional cardiology in Switzerland during the year 2007. Kardiovasculare Medizin 2010; 13(1) 18-24

28. Meredith IT, Verheye $S$, Weissman NJ, Barragan P, Scott D, Valdés Chávarri M,West NE, Kelbæk H, Whitbourn R, Walters DL, Kubica J, Thuesen L, Masotti M,Banning A, Sjögren I, Stables RH, Allocco DJ, Dawkins KD. Six-month IVUS and two-year clinical outcomes in the EVOLVE FHU trial: a randomised evaluation of a novel bioabsorbable polymer-coated, everolimus-eluting stent. Eurolntervention 2013; 9(3):308-15.

29. Sarno G, Lagerqvist B, Frobert O, et al. Lower risk of stent thrombosis and restenosis with unrestricted use of new-generation drug-eluting stents: a report from the nationwide Swedish Coronary Angiography and Angioplasty Registry (SCAAR). Eur Heart J 2012; 33:606-13.

30. Camenzind E, Steg PG, Wijns W. Stent thrombosis late after implantation of first-generation drug-eluting stents: a cause for concern. Circulation. 2007; 115(11):1440-55;

31. A. Colombo, wine production. http://www.colombovino.it/en/

32. Diamond GA, Kaul S. COURAGE under fire: on the management of stable coronary disease. J Am Coll Cardiol. 200;50(16):1604-9.

33. Read more: http://medcitynews.com/2011/06/ end-of-jj-stent-business-carries-lessons-for-medical-deviceinnovators/\#ixzz2wa6zYtF8

34. Harvard Law. http://weblaw.usc.edu/assets/docs/contribute/ MedicalStent.pdf

35. Reifart N. Chronic total coronary occlusion percutaneus intervention. Eur Hear J 2014; $9: 1139-1140$

36. Finci L, Meier B, Favre J, Righetti A, Rutishauser W. Long-term results of successful and failed angioplasty for chronic total coronary arterial occlusion. Am J Cardiol 1990; 66(7):660-2.

37. Meier B, Carlier M, Finci L, Nukta E, Urban P, Niederhauser W, Favre J. Magnum wire for balloon recanalization of chronic total coronary occlusions. Am J Cardiol 1989; 64(3):148-54.

38. Goldberg SL, Colombo A, Maiello L, Borrione M, Finci L, Almagor $Y$. Intracoronary stent insertion after balloon angioplasty of chronic total occlusions. J Am Coll Cardiol 1995; 26(3):713-9.

39. Mehran R, Claessen BE, Godino C, Dangas GD, Obunai K, Kanwal S, Carlino M, Henriques JP, Di Mario C, Kim YH, Park SJ, Stone GW, Leon MB, Moses JW, Colombo A; Multinational Chronic Total Occlusion Registry. Long-term outcome of percutaneous coronary intervention for chronic total occlusions. JACC Cardiovasc Interv 2011;4(9):952-61.

40. De Felice F, Fiorilli R, Parma A, Musto C, Nazzaro MS, Scappaticci $\mathrm{M}$, Confessore P, Guerra E, Belloni F, Violini R. Five-year outcomes in patients with chronic total coronary occlusion treated with drug-eluting vs bare-metal stents: a case-control study. Can J Cardiol 2013;29(8):945-7.

41. Valenti R, Vergara R, Migliorini A, Parodi G, Carrabba N, Cerisano G, Dovellini EV, Antoniucci D. Predictors of reocclusion after successful drug-eluting stent-supported percutaneous coronary intervention of chronic total occlusion. J Am Coll Cardiol 2013;61(5):545-50.

42. Syllabus JIM 2014, Rome, Italy 14-18 Feb 2014

43. Serruys PW, BVS Extend: An Interim Report on the 12-Month Clinical Outcomes from the First 450 Patients Registered, Presented at: Euro PCR, Paris, France, 21-24 May 2013.

44. Stone GW. Bioresorbable vascular scaffolds: is imaging everything? Euro Intervention 2014 Mar 20;9(11):1255-7.

45. Finci Z. Sefardski Nocturno. Veselin Maslesa Pbl. Sarajevo, 1990. ISB 86-21-0042244 